El presente escrito teje algunas reflexiones en torno a cómo concebir y posicionarnos colectivamente ante las muertes y las pérdidas a raíz del CoviD-19. Al final, se resalta una lista de herramientas específicas que ayudan con la elaboración del duelo.

Palabras clave: cultura, muerte, duelo, trabajo emocional, Covid-19

\title{
¿Bailar con la más fea? \\ Duelo y muerte en el contexto gCOVID-19
}

\section{Serena Eréndira Serrano Oswald sesohi@hotmail.com}

No temas a la muerte y no temerás a la vida Epicuro

Desde los tiempos más remotos, el tema de la muerte ha ocupado un lugar preponderante en las sociedades humanas, la muerte nos civiliza. Como afirma Caycedo, "la muerte es un ejemplo paradigmático de un hecho social” (2007, p. 332). Es decir, todas las personas tenemos la certeza de que vamos a morir y que a lo largo de nuestro ciclo vital habrá muertes - y muerte- alrededor nuestro. El contexto social en el que ocurra será definitorio en nuestra forma de pensar, actuar y sentir. Así, la preparación del cuerpo, los ritos funerarios, el luto, el duelo, así como las creencias y la forma en que conducimos nuestras vidas están estrechamente ligadas con nuestra visión del mundo y su concepción de muerte. Pero ¿̇en qué contexto y circunstancias aparece ahora el fenómeno del coronavirus?

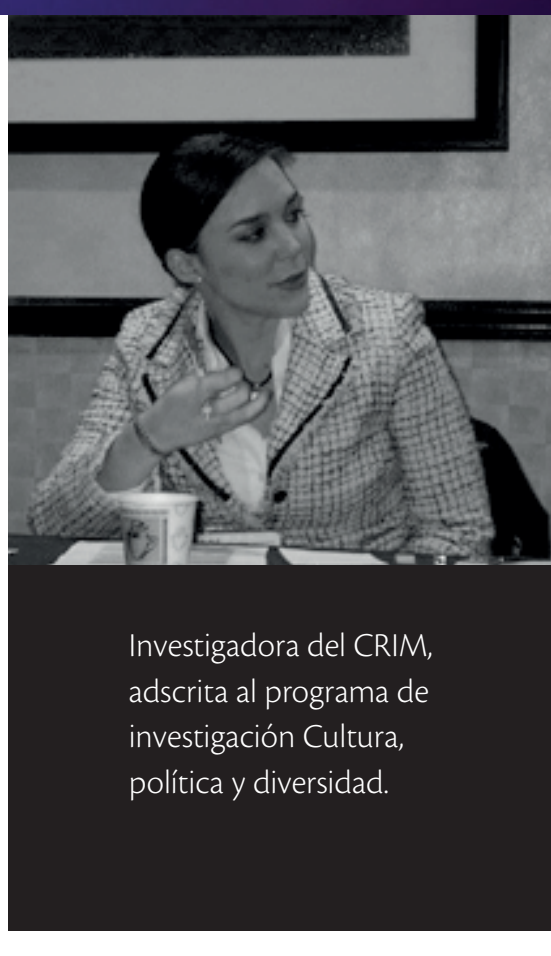


El covid-19 es una enfermedad altamente contagiosa que se genera a raíz del virus SARS-CoV-2 y que hizo su aparición apenas en diciembre de 2019. Cuatro meses después, ha contagiado a más de tres millones de personas confirmadas, matando a más de 215000 entre ellos -y la cuenta continúa incrementándose. Ha sido catalogada como la pandemia más importante de los últimos cien años. Los Gobiernos y los grupos sociales han reaccionado de diversas formas para hacerle frente, con mayor o menor éxito. Hay iniciativas muy importantes para mitigar sus efectos de salud y socioeconómicos, pero todavía nos falta develar muchos aspectos ligados al covid-19. Es innegable que además de la tranquilidad, a todos nos ha ocasionado ya múltiples pérdidas. El coronavirus ha penetrado en nuestra vida cotidiana, afectando nuestras relaciones, salud, trabajo, economía, cultura, etc. Incluso, ha irrumpido en nuestra capacidad de manejar la muerte. Por ello es que una reflexión en torno a la muerte y el duelo, así como algunas pautas facilitadoras se vuelven pertinentes. Parafraseando a Edgar Jackson, lo importante es lo que hacemos con lo que la vida nos hace. Hablaré entonces primero de muerte y posteriormente de duelo, resiliencia y elaboración de pérdidas. De antemano, una disculpa por las generalizaciones.

La muerte es universal, pero las formas de morir y significar la muerte se definen social y culturalmente. Por supuesto, tienen matices únicos en cada sujeto individual y grupal (en cada familia, comunidad, o a nivel societal). Se trata así de un proceso dinámico, y se reconfigura al igual que la cultura. La naturaleza de los rituales funerarios tiene una relación estrecha con el contexto en el que acaecen. El luto en contextos como el nuestro es la cara institucionalizada de los ritos de muerte, sus comportamientos y la forma de significar la vida misma se expresan en él. En cambio, por duelo se entiende la vivencia subjetiva y los sentimientos ocasionados por la muerte.

En sociedades post-industriales occidentales utilitaristas y pragmáticas que favorecen la productividad, la juventud y la hiper-tecnologización la muerte es un enemigo silencioso, invisible. Se le visibiliza al parecer primordialmente sólo por morbo. Importa la intensidad hedónica de la vida. Se trata de contextos en los que de por sí se desdeña a los seres humanos a quienes se les mira como productores y consumidores, y en los que las mujeres frecuentemente no pasan de ser objetos - seguido desechables. Pierden interés la creatividad y la sacralidad en la cultura humana. Los resultados se miden por la eficiencia, las transacciones sustituyen a las comunidades y los tiempos del tiempo (Boscolo y Bertrando, 1993) se tornan histéricamente expeditos; no permiten el contacto ni la asimilación en el ciclo de la experiencia. Vale consumir voraz y velozmente al costo que sea, como careta, sin satisfacer necesidades de fondo: tener en lugar de ser es el mensaje audible. La vejez no encaja, el dolor disgusta, la enfermedad incomoda, incluso hablar lento exacerba. Hay grandes y millonarios negocios funerarios, eso sí, pero la muerte en cuanto muerte no conviene, es el adversario que nos derrota y por ende es censurable, no se nombra, se evade. Sobre la 'autodestructiva negación de la muerte' Philippe Ariès afirma "como ya no se muestran señales externas de estar de luto, la sociedad no 've' a los que lloran la muerte de un ser querido" (citado en Caycedo, 2007, p. 337).

Esto contrasta con Heidegger quien veía que el ser humano "es un ser para la muerte". Lejos quedó lo sobrenatural y lo trascendente, "la familiaridad de la muerte, el consuelo espiritual y el entierro alrededor de los santos en las mismas 
ciudades cuyo marco de comprensión es la Iglesia" (Felipe Mendoza, 2009). Antes, la vida social giraba en torno de la relación vida-muerte. Hoy, en contextos "desarrollados" y "à la carte", a las personas "por su bienestar" se les manda a morir solas a instituciones especializadas en manejos técnicos, desplazadas de la vida familiar y social, sin que tengan capacidad de decidir sobre su muerte. La tecnología, por más avanzada, no evita la muerte aunque es muy eficiente, igual que los psicofármacos o las sustancias adictivas, para interrumpir el dolor, la elaboración del duelo y la incertidumbre que genera la muerte. Total que nos desensibilizamos aterrados evitando los malestares que proyectamos en la muerte. Hay dos paradojas curiosas: desdeñamos la vejez pero queremos que la tecnología nos ayude a vivir más, sólo vivir más, nunca mejor. Ni hablar de morir bien. Además, resulta que en la tradición judeocristiana la vida "eterna" se concibe como una sublimación de la vida "terrena" y sin embargo la muerte nos horroriza. Desde una concepción en la que "todo está escrito" (típica sobre todo de líneas protestantes y/o judías), sin considerar a fondo el libre albedrío, ya no es deseable hacer méritos, tratar bien al prójimo, a nosotros mismos. Ni hablar de indulgencias.

Oriente guarda otra relación con la muerte mucho más continua. En el Budismo la vida es transitoria, tiene diversas fases. La vida terrena transmuta. El universo está en cambio constante y la muerte es un presente respetado, nos ayuda a estar aquí y ahora. Nada se crea ni se destruye, sólo se transforma en un ciclo interminable de decadencia y renovación. La vida es eterna, como la flor del cerezo que está latente aunque no visible en invierno. A lo largo de la vida se practica y perfecciona el arte de morir, como uno de los procesos más importantes de la vida que permiten o no liberar al alma. Por ejemplo en el Bardo Thödol (Libro Tibetano de los Muertos), en el que la muerte se trata con respeto y veneración, en el que la muerte estimula la vida, las buenas causas, la bondad y la humanidad. Se muere en compañía de guías que permiten soltar, ir más allá y dejar todas las anclas con esta vida. En el Hinduismo la muerte no es el enemigo porque el ser pertenece a la eternidad y es una manifestación divina. Existe el renacimiento, lo que se busca es liberarse de la vida terrena como terrena, renunciar al mundo ilusorio, interrumpir la cadena y unir el alma individual con el alma universal. Todo es resultado de acciones pasadas y todo lo que hacemos tiene consecuencias. Gandhi nos dice "vive como si fueras a morir mañana. Aprende como si fueras a vivir siempre".

\section{ca}

En el Islam la muerte es jus-

La coyuntura del CoviD-19 nos permite

generar procesos de resiliencia social sistémica

\section{en torno a la vida-muerte}

ta, porque pone en evidencia que somos iguales ante Dios y que nadie escapará de la muerte. Las obras de la vida preparan para la muerte, para el juicio de Allá (de Alá), para el paraíso o el infierno.

Se da primacía a lo espiritual sobre lo material y las personas se llevan sus obras, su caridad, el conocimiento que hayan compartido y que pervive, así como una descendencia que les honre y les rece. El alma queda atada si tiene deudas. Más que como religión, el Corán se toma como forma de vida y de muerte, dado que especifica muy claramente las ceremonias y ritos de muerte, que se viven colec- 
tivamente. La cremación no es alternativa en el rito de preparación del cuerpo, plegarias y entierro, dado que en el entierro, en el suelo se completa el ciclo vital.

México es visto en el extranjero como un país en el que la vida tiene una estrecha relación con los muertos. Es más, por los ritos, altares, ceremonias y tradiciones de Día de Muertos, se dice que en nuestro país se hace una 'fiesta nacional' a los muertos. Esta percepción ha crecido a raíz del éxito de la película de Coco o a raíz del desfile con cientos de miles de personas a partir de la película Spectre de James Bond en la Ciudad de México. Aunque hay matices regionales, de clase, religiosos, etc. la muerte en México es sincrética, tiene elementos prehispánicos, católico-cristianos, rural-agrícolas y de narco-cultura.

En las sociedades prehispánicas, la muerte tenía una carga de equilibrio dinámico colectivo, la muerte como parte inalienable de la vida. Morir garantizaba la vida en la tierra y el equilibrio del ciclo del universo. El inframundo era femenino, aunque el señor de los muertos decidiera el destino final de las almas. A diferencia del modelo médico vigente, los sacerdotes y chamanes trabajaban para restaurar equilibrios cosmogónicos, no sólo para equilibrar la vida individual. Para ello eran necesarios ritos, sacrificios, festividades, of rendas, alimentos, flores, objetos de acompañamiento postmortem.

Actualmente, en el contexto de desigualdad, violencia estructural y social, pareciera que la vida vale poco. Lo que no se nombra no existe, y así como evitamos hablar de la muerte, evitamos hablar de las personas que a causa de la desigualdad y la violencia están atravesados por "proyectos de muerte", vulnerados en su capacidad de vivir y gozar salud, desarrollarse, cumplir sus necesidades básicas, ni pensar en realizarse. Crece el culto a la Santa Muerte y los ritos emergentes se ligan con la violencia social y la narco-cultura. La violencia se ha tornado una epidemia social, naturalizada, por ejemplo en enero de 2020 hubo 2819 homicidios dolosos y 73 feminicidios. Han muerto más mujeres por feminicidio que por covid-19. La pandemia por coronavirus nos tiene encerrados en casa, a las mujeres enfrentando mayores índices de violencia doméstica, pero las actividades criminales, las balaceras y los homicidios no cesan. Además, nos encontró hechos un país obeso, diabético, hipertenso, adicto, inmunodeprimido, etcétera.

Posiblemente, si algo interesante nos pueda dejar la coyuntura del covid-19 es a generar procesos de resiliencia social sistémica en torno a la vida-muerte. Quizá vale la pena detenernos, conectar, repensarnos y regenerarnos desde ahí. ¿Necesitamos bailar con la más fea? ¿Verdaderamente será la más fea? $¿$ Realmente se acaba la música y se termina el baile? La resiliencia es la capacidad adaptativa de un sistema para hacer frente al cambio y las perturbaciones, adaptándose y manteniendo su funcionamiento. Típicamente la resiliencia se

ca

La pandemia es una oportunidad de re-pensarnos y

organizarnos a nivel individual, familiar y social.

La violencia al igual que el maltrato es un ciclo vicioso,

genera más violencia. Romper ese ciclo y transitar

conscientemente hacia el buen trato es un imperativo entiende a nivel individual, aunque me parece muy importante ampliar la definición (Walsh, 2005). Propongo entender a la resiliencia como la capacidad humana (individual, familiar, comunitaria, societal) y a largo plazo de sobreponerse a cambios y adversidades, haciéndoles frente, 
creciendo a partir de ello. Se trata de un proceso dinámico, de retroalimentación particular, coherente, de desarrollo y potencial que nos permite salir con aprendizajes y herramientas de una crisis. No significa la invulnerabilidad ni implica la incompetencia de quien no logra ajustarse. Es sistémica. Lo que sí, la resiliencia se origina en las crisis, no en los lugares cómodos.

Es decir, la pandemia es una oportunidad de repensarnos y organizarnos a nivel individual, familiar y social. La violencia al igual que el maltrato es un ciclo vicioso, genera más violencia. Romper ese ciclo y transitar conscientemente hacia el buen trato es un imperativo de deconstrucción y reconstrucción. Ese es el enorme potencial de este momento. No nos está yendo muy bien con lo conocido. No sabemos bien vivir y tampoco hemos aprendido a morir dignamente. En ocasiones las experiencias traumáticas colectivas de muerte resignifican la vida y la muerte misma. $\mathrm{Si}$, aunque mínimamente, logramos integrar procesos de bien vivir y bien morir, seguramente esta experiencia nos dejará con ma-

a

El covID-19 es una oportunidad, como lo fue

la tremenda peste europea (1348-1362) que no sólo hizo factible sino que abrió las puertas al grande e ilustre época del Renacimiento, de replantear nuestros objetivos y sistemas de vida social y personal más acordes con las necesidades de una mejor vida y mejor muerte con que nos aproximemos al 'buen yores aprendizajes y herramientas que en el pasado. Tendremos mayor consciencia y agencia para vivir y morir con dignidad. Esto apuntaría a que colectivamente nos revisemos y transitemos a un mayor estado de salud. Sabremos que las respuestas son colectivas, aunque requieren esfuerzos cotidianos individuales y grupales.

E1 covid-19 es una oportunidad, como lo fue la tremenda peste europea (1348-1362) que no sólo hizo factible sino que abrió las puertas a la grande e ilustre época del Renacimiento, de replantear nuestros objetivos y sistemas de vida social y personal más acordes con las necesidades de una mejor vida y mejor muerte con que nos aproximemos al "buen vivir".

E1 24 de marzo de 2020 la Organización Mundial de la Salud presentó una guía acerca del manejo técnico de los muertos por covid-19. Los familiares pueden ser cremados o enterrados si no se toca su cuerpo. Hay países que se debaten entre cremar o enterrar a sus muertos siguiendo sus ritos funerarios. En México, la cremación es deseable, pero por proteger los derechos humanos de miles de desaparecidos se tuvo que acotar la recomendación a no permitir la cremación de cuerpos no identificados. Hay protocolos estrictos para las personas gravemente enfermas que implican aislamiento hospitalario (las personas no podrán ser visitados para proteger la vida de familiares-amistades). Si las personas pierden la vida, los protocolos de bioseguridad para los cadáveres implican que una vez identificado, a los deudos no se les permitirá ver el cuerpo, lo que tanatológicamente se ha observado que dificulta el proceso de elaboración de duelo.

Hay tres tipos de duelo que son particularmente difíciles, los duelos traumáticos, los duelos congelados y los duelos ambiguos. En los duelos congelados la situación nos duele y desborda a tal grado que optamos por pensar que después los elaboraremos. En los duelos traumáticos las circunstancias a veces dificultan el procesamiento del duelo. Las pérdidas ambiguas son pérdidas que 
ca

Hay tres tipos de duelo que son particularmente

difíciles, los duelos traumáticos, los duelos congelados

y los duelos ambiguos. El coronavirus presenta

escenarios múltiples de este tipo de pérdidas." permanecen poco claras, que no se pueden arreglar y no tienen resolución, por ello son las pérdidas más difíciles. Ante la incertidumbre, el misterio, el trauma, etc. se dificulta la resolución y la elaboración del duelo. El coronavirus presenta escenarios múltiples de este tipo de pérdida, mismo que no es un entrenamiento habitual entre tanatólogos en México, por ello es importante destacarlo. El enfoque, desarrollado por Pauline Boss (1999, 2004, 2006, 2011) considera dos tipos de pérdida y siempre son abordados de forma relacional: "Irse sin despedirse" (ausencia física con presencia psicológica, por ejemplo en secuestros, desapariciones, asignaciones militares, divorcios, cuarentenas, desastres) y "despedirse sin irse" (presencia física con ausencia psicológica, por ejemplo, enfermedades, demencia, adicciones, depresión, autismo, infidelidad, divorcio, obsesión por las tecnologías y celulares). De cara al momento particular, considero pertinente apuntar algunas cosas muy concretas:

1. El duelo más difícil es el que no se hace (ej. el que se congela, el que es ambiguo y el que tiene características de trauma. En este caso del coVID-19 se pueden cumplir los 3 criterios, por lo que es muy importante buscar ayuda profesional en su momento si es el caso);

2. Pongamos desde ya en orden nuestros asuntos con los demás significativos, hablemos hoy, no cuando estemos intubados y moribundos (es de por sí muy sanador hacerlo);

3. Conversemos abiertamente acerca de la enfermedad y la muerte, de si queremos ser intubados o no, ir al hospital, donar órganos, dejar qué deudas, etcétera (esto no significa fantasear o invitar a la muerte, es actuar como adultos en medio de una grave crisis);

4. Si no es posible o deseable conversar hoy, una buena opción es empezar a hacer una carta de despedida para cada persona significativa (este ejercicio tanatólogico nos ayuda a organizar y procesar muchos temas pendientes, a darnos cuenta. Si tiene hijos pequeños o adolescentes, hágalo, por favor deje una carta de despedida para cada uno. Esto les puede cambiar la vida y el proceso de duelo a sus deudos y ser un recurso de por vida. Si no muere, puede destruirla o idealmente reescribirla cuando su contenido ya no sea vigente. No disponga la entrega a menos que muera);

5. Seamos sensibles con infantes y ancianos (hay que establecer diálogos respetuosos, empáticos, centrados en sus necesidades y cuidar el uso de lenguaje. Para los infantes el uso de lenguaje metafórico no va acorde con su etapa de desarrollo y entienden de manera literal lo dicho. Si conversa con infantes de muerte -lo cual es muy importante hacer en estos tiempos- no diga frases como "me estoy preparando para la muerte/morir" porque pueden asustarse al no entender que está desarrollando un ejercicio de salud mental o tanatológico y se puede generar pánico y trauma innecesario); 
6. Ayuda mucho procesar y trabajar con secretos familiares transgeneracionales desde ya (no heredemos más problemas, rompamos ese ciclo);

7. Si tiene tiempo, lea sobre tanatología y comparta reflexiones en casa (recuerde que distancia física no equivale a distancia emocional);

8. Haga una carpeta que ayude a sus familiares a hacer trámites si muere: con sus documentos oficiales, testamento, seguros, documentos de trabajo, escrituras, etcétera (hagan acuerdos claros sobre responsabilidades y bienes si no hay testamento)

9. Si hay personas que requieren cuidados continuos o si usted es cuidador primario, establezcan un plan b por si usted fallece;

10. Establezca y comunique qué rituales de muerte sí podrían hacerle en un futuro, cuando pase la contingencia, en caso de que usted muera.

Me gustaría cerrar citando a la madre de la Tanatología moderna, Elisabeth Kübler-Ross quien nos dice que "No se puede sanar al mundo sin sanarse primero a sí mismo" y nos invita a "Aprende a ponerte en contacto con el silencio dentro de ti y saber que todo en esta vida tiene un propósito. No hay errores, no hay coincidencias; Todos los eventos son bendiciones que se nos dan para aprender”. Así pues, en el contexto del covid-19, aprendamos los unos de los otros y aprendamos de la vida y de la muerte.

\section{Referencias bibliográficas}

Boscolo, L. y Bertrando, P. (1993). Times of Time. Nueva York: W.W. Norton. Boss, P. (2000). Ambiguous Loss: Learning to Live with Unresolved Grief.

Cambridge, Massachusetts: Harvard University Press. (2004). Ambiguous Loss Research, Theory, and Practice: Reflections After 9/11. Journal of Marriage E Family, 66 (3): 551-566. (2006). Loss, Trauma, and Resilience: Therapeutic Work with Ambiguous Loss. Nueva York: Norton. (2011). Loving Someone Who Has Dementia. San Francisco: JosseyBass/Wiley.

Caycedo Bustos, M. L. (2007), La muerte en la cultura occidental: antropología de la muerte, Revista Colombiana de Psiquiatría, 36(2): 332-339.

Felipe Mendoza, J. A. (2009). Philippe Aries: Morir en Occidente, mimeo. Moody, R. (1975). Life After Life. EUA: Mockingbird Books.

Walsh, F. (2005). Resiliencia familiar: estrategias para su fortalecimiento. Madrid/Buenos Aires: Amorrortu.

Para citar esta nota: Serrano Oswald, S. E. (6 de mayo de 2020). ¿Bailar con la más fea? Duelo y muerte en el contexto del covid-19. Notas de coyuntura del CRIM No. 7, México, 